\title{
Role of crustal thickness in the formation of Au-rich porphyry deposits
}

\author{
HONGDA HAO ${ }^{1}$, JUNG-WOO PARK ${ }^{1}$ AND IAN H. \\ CAMPBELL $^{2}$
}

${ }^{1}$ Seoul National University

${ }^{2}$ Australian National University

Presenting Author: hongda@snu.ac.kr

Porphyry deposits, the world's most significant source of $\mathrm{Cu}$ and an important source of $\mathrm{Au}$ [1], are formed by precipitation of $\mathrm{Cu}$ and $\mathrm{Au}$ from magmatic hydrothermal fluids. Some porphyry deposits contain $\mathrm{Au}$ as major resources, but the others as byproducts [2]. The high Au endowments in the porphyry deposits significantly increase the deposits value. However, the key factors that control the $\mathrm{Au}$ enrichment in porphyry systems remains unclear. Magmas traversing the thick crust are likely to become sulfide-saturated early [3, 4], due to the high-pressure differentiation and low $\mathrm{Fe}$ content, which decrease the sulfur solubility in silicate melts $[5,6]$. Early sulfide saturation locks most of $\mathrm{Au}$ and some $\mathrm{Cu}$ in the sulfide phases that are retained in the lower crustal cumulates. The evolving magma will be significantly depleted in $\mathrm{Au}$, but it may contain enough $\mathrm{Cu}$ to form a porphyry $\mathrm{Cu}$-dominant deposit. In contrast, magmas evolving in the thin crust are suggested to reach sulfide saturation late $[3,4]$, so that most of the $\mathrm{Cu}$ and $\mathrm{Au}$ may be available by the time of fluids exsolution, favoring the formation of Au-rich porphyry deposits. Based on this relationship, we collect the global Au grade and crustal thickness data of giant porphyry deposits and show they are generally negatively correlated. As a consequence, we suggest that the Au fertility, which is dominantly controlled by the timing sulfide saturation and modulated by the crustal thickness, plays a critical role in the formation of Au-rich porphyry deposits.

References:

[1] Sillitoe, R. H. (2010). Economic geology 105, 3-41.

[2] Cooke, D. R., Hollings, P., \& Walshe, J. L. (2005). Economic geology 100, 801-818.

[3] Chiaradia, M. (2014). Nature Geoscience 7, 43-46.

[4] Lee, C. T. A., \& Tang, M. (2020). Earth and Planetary Science Letters 529, 115868.

[5] O'Neill, H. S. C., \& Mavrogenes, J. A. (2002). Journal of Petrology 43, 1049-1087.

[6] Matjuschkin, V., Blundy, J. D., \& Brooker, R. A. (2016). Contributions to Mineralogy and Petrology 171, 1-25. 